\title{
Cardio-renal protection of riociguat (BAY 63-252I) in low- and high-renin models of hypertension
}

Philipp Kalk1,2, Yuliya Sharkovska ${ }^{2}$, Bettina Lawrenz ${ }^{3}$, Michael Godes², Linda Sarah Hoffmann ${ }^{4,5}$, Kathrin Wellkisch ${ }^{2}$, Sandra Geschka $a^{4,6}$, Katharina Relle ${ }^{2}$, Berthold Hocher ${ }^{2}$ and Johannes-Peter Stasch ${ }^{* 4,5}$ \author{
D-50931 Cologne, Germany \\ Email: Johannes-Peter Stasch* - johannes-peter.stasch@bayerhealthcare.com \\ * Corresponding author \\ from 4th International Conference of cGMP Generators, Effectors and Therapeutic Implications \\ Regensburg, Germany. 19-21 June 2009 \\ Published: II August 2009 \\ BMC Pharmacology 2009, 9(SuppI I):P30 doi:I0.1186/147I-2210-9-SI-P30
}

Address: ${ }^{1}$ Department of Nephrology, Charité, Campus Benjamin Franklin, Hindenburgdamm 30, Berlin, Germany, ${ }^{2}$ Center for Cardiovascular Research, Department of Pharmacology and Toxicology, Charité, Campus Mitte, Hessische Str. 3-4, Berlin, Germany, ${ }^{3}$ Pathology, Research Centre, Bayer HealthCare, Aprather Weg 18a, Wuppertal, Germany, ${ }^{4}$ Cardiology Research, Bayer HealthCare, Aprather Weg $18 \mathrm{a}$, Wuppertal, Germany, ${ }^{5}$ Martin-Luther-University, School of Pharmacy, Halle, Germany and ${ }^{6}$ Department of Pharmacology, University of Cologne, Gleueler Strasse 24 ,

This abstract is available from: http://www.biomedcentral.com/I47I-22 I0/9/SI/P30

(c) 2009 Kalk et al; licensee BioMed Central Ltd.

\section{Background}

Riociguat (BAY 63-2521) is a direct NO-independent stimulator of soluble guanylate cyclase (sGC) and is being investigated as a new therapeutic approach for the treatment of different forms of pulmonary hypertension in clinical phase III trials. The NO-sGC-cGMP signal transduction pathway is impaired in different cardiovascular diseases, including pulmonary hypertension, heart failure and arterial hypertension. We thus investigated the cardio-renal protective effects of riociguat in low-renin and high-renin rat models of hypertension.

\section{Materials and methods}

The cardiovascular consequences of sGC stimulation were evaluated by the long-term effects of riociguat in hypertensive renin-transgenic (TG(mRRen2)27) rats treated with the NOS inhibitor N-nitro-L-arginine methylester (LNAME). This high-renin study lasted 18 days and contained 3 groups: control $(\mathrm{n}=24), 3 \mathrm{mg} / \mathrm{kg}(\mathrm{n}=12)$ and $10 \mathrm{mg} / \mathrm{kg}(\mathrm{n}=12)$ riociguat orally once daily. Rats with $5 /$ 6 nephrectomy (5/6 NX) were used as low-renin model of hypertension. This low-renin study lasted 18 weeks and contained 3 groups: 5/6 NX ( $\mathrm{n}=15), 5 / 6 \mathrm{NX}+$ riociguat (300 ppm in the solid feed; $\mathrm{n}=12$ ) and sham-operation $(\mathrm{n}=10)$. Blood pressure was assessed via tail-cuff repeatedly, at the end of the study all animals were sacrificed, blood and organ samples were harvested for further studies.

\section{Results}

In the high-renin study part, the beneficial effects of riociguat are emphasized by a significantly increased survival in both dosages (riociguat low dose: 92\%, riociguat high dose: $100 \%$ vs $46 \%$ in L-NAME treated rennin transgenic rats). In the low-renin study, overall survival was higher: $5 / 6 \mathrm{NX} 60 \%$, 5/6 NX + riociguat $73 \%$, sham $100 \%$. In both models the blood pressure was significantly reduced by riociguat. Moreover, in the high-renin study part riociguat reduced cardiac target organ damage as indicated by lower plasma ANP, lower relative left ventricular weight and lower cardiac interstitial fibrosis and reduced renal target organ damage as indicated by lower plasma creatinine and urea, less glomerulosclerosis and less renal interstitial fibrosis. In the low-renin study part riociguat reduced cardiac target organ damage as indicated by lower plasma ANP, lower relative left ventricular weight, lower myocyte diameter and lower arterial media/lumen ratio and reduced renal target organ damage as indicated by 
improved creatinine clearance and less renal interstitial fibrosis.

\section{Conclusion}

We demonstrate for the first time that the novel sGC stimulator riociguat shows in two independent models of hypertension a potent protection against cardiac and renal target organ damage.

Publish with Bio Med Central and every scientist can read your work free of charge

"BioMed Central will be the most significant development for disseminating the results of biomedical research in our lifetime. " Sir Paul Nurse, Cancer Research UK

Your research papers will be:

- available free of charge to the entire biomedical community

- peer reviewed and published immediately upon acceptance

- cited in PubMed and archived on PubMed Central

- yours - you keep the copyright 